\title{
eIF4G and CBP80 share a common origin and similar domain organization - implications for the eIF4G structure and function
}

\section{Supporting Information}

\section{Sequence and structure analysis}

Sequence homology searches were performed using PSI-BLAST (1). The sequences were assigned to individual families of eIF4G homologs (see Fig. 1B), based on sequence homology, without using information from the corresponding database entry, because some sequences were misannotated in the databases or the nomenclature was ambiguous. Sequences belonging to the same or closely related families were typically recovered with one or two PSI-BLAST iterations, whereas detection of homology to members of distant families (e.g., between the HEAT-1/MIF4G domains of eIF4G and CBP80, Fig. S1A) required exhaustive PSI-BLAST searches. Where the assignment of a target sequence to a family was not obvious, a new BLAST search was initiated from that sequence. Searches of unfinished eukaryotic genomes were done using TBLASTN (2).

Multiple sequence alignments were produced using a combination of T-COFFEE (3), CLUSTAL W (4) and the PSI-BLAST output, with manual adjustments. Sequence alignment between the corresponding HEAT domains of eIF4G and CBP80 was based on structure alignment from the DALI server (5). The vertebrate eIF4G, NAT1 and CBP80 sequences shown in Fig. S1A and B were used for most analyses.

Searches for structural homologs and pair-wise structure alignments were done using the DALI server. Analysis and display of the structures was done in MOLMOL (6).

\section{Evolutionary relationships among eIF4G homologs}

Most of the families of eIF4G homologs identified by PSI-BLAST searches were as reported previously (7-9). New family members from recently sequenced genomes were identified. Here, we have limited our attention to proteins relevant to the hypothesis that eIF4G and CBP80 have evolved from a common ancestor that already contained three consecutive HEAT domains. For example, NMD2, which has three MIF4G domains, is not discussed, because its origin cannot be inferred in the same way as that of eIF4G and CBP80. PAIP1, which contains a single HEAT/MIF4G domain, is discussed only in relation to the PABP-interacting motif 2 (PAM-2) peptide found N-terminal from its HEAT/MIF4G domain (see below). The discussion below and in the main text relies in part on the notion that the statistical probability for the same domains to be fused to each other in different proteins multiple times during evolution is negligibly small. Therefore, it is presumed that if the same domain organization is found in evolutionarily distant proteins, but not in some more closely related proteins, the domains were fused together in a common ancestor, and later individual domains were lost in certain branches of the evolutionary tree, but retained in others.

\section{Domain organization of eIF4G orthologs}

eIF4G from human and other vertebrates contains three consecutive HEAT domains: HEAT-1/MIF4G, HEAT2/MA3 and HEAT-3/W2 ((10) and PDB entry 1UG3, S. Burley, unpublished). Both plant eIF4G isoforms contain the first two HEAT domains, but lack the HEAT-3/W2 domain, whereas the yeast ( $S$. cerevisiae and $S$. pombe) eIF4G isoforms only have the first, HEAT-1/MIF4G domain (7-9). We found that whereas most fungal eIF4G sequences contain only the HEAT-1/MIF4G domain, all Basidiomycete eIF4Gs also contain a HEAT2/MA3 domain, including those from several unfinished fungal genomes available in the databases (accession 
numbers for the two eIF4G isoforms from C. neoformans strain B3501A: EAL23255 and EAL23238). This observation suggests that the HEAT-2/MA3 domain was present in early eukaryotes and subsequently lost in most fungi, after Basidiomycetes branched from the other fungal lineages. eIF4G sequences containing both the HEAT-1/MIF4G and the HEAT-2/MA3 domains are even found in some more primitive eukaryotes, such as Dictyostelium (accession number for the D. discoideum eIF4G: EAL69763), which indicates that at least these two HEAT domains were present in eIF4G very early in evolution. Identification of the true eIF4G orthologs based on sequence alone in other primitive eukaryotes is not always straightforward (see for example reference (11) for eIF4G in Trypanosomatidae). Interestingly, the two sequences judged by the authors of that study to be the most likely eIF4G orthologs appear to have both a HEAT-1/MIF4G and HEAT-2/MA3 domains. Whereas all known insect eIF4G sequences contain all three HEAT domains, the two available nematode eIF4G sequences (C. elegans, accession number 23748, and C. briggsae, accession number CAE57703) lack the HEAT-3/W2 domain.

\section{Domain organization of distant eIF4G homologs}

Both a HEAT-1/MIF4G and a HEAT-2/MA3 domain are found in the NOM1 family (the accession number for human NOM1 is AAT39521) and the closely related family, represented by the $S$. pombe cell cycle control protein cwf22 (accession number Q9P6R9) and human KIAA1604 (accession number AAH57826), as previously predicted (9). Thus, the common ancestor of eIF4G and NOM1 must have contained both the HEAT-1/MIF4G and the HEAT-2/MA3 domains.

CBP80 was found in most eukaryotic genomes, including some primitive eukaryotes, like Dictyostelium (accession number for D. discoideum: EAL72257). It appeared that in all species CBP80 contained all three HEAT domains found in the crystal structure of human CBP80 (12-14), and no multiple isoforms were identified. This is in contrast to eIF4G, which contains either one, two or all three HEAT domains in different species, and is often present in more than one isoforms. Consistent with previous data $(8$, 9), no sequence homology could be detected between the HEAT-2 and HEAT-3 domains of eIF4G and CBP80, despite their high degree of structure conservation (see Fig. 2B and Table S1). In contrast, the conservation between eIF4H and CBP20 was readily observable (27\% identity, 37\% conservation) over the entire CBP20 sequence (eIF4H has a C-terminal extension absent in CBP20, see Fig. S1E).

Searches for structural homologs and pairwise comparisons of available HEAT domain structures, using the DALI server, indicated that the HEAT-1/MIF4G domains of CBP80 and eIF4G were most similar to each other (Table S1) as well as to the MIF4G domain of NMD2, as expected from their distant sequence homology. The closest structural homologs of the HEAT-3 domain of CBP80 were the HEAT-3/W2 domains of eIF4G and eIF2B $\varepsilon$, and vice versa. Similarly, the HEAT-2 domain of CBP80 and the HEAT-2/MA3 domain of eIF4G were most closely related to each other. Remarkably, the structure similarity for the domain pairs with no detectable sequence homology (e.g., between the HEAT-3 domains of eIF4G and CBP80) was comparable to that between the homologous HEAT-1/MIF4G domains (Table S1). These results indicate that these three consecutive HEAT domains were already present in the common ancestor of eIF4G and CBP80 early in eukaryotic evolution. The next most similar structures (to eIF4G and CBP80) identified by the DALI server with $Z$ scores of 8.5 , were importin- $\beta$, a large horseshoe-shaped HEAT-repeat protein ((15), PDB code 1QGR) and the RNA polymerase 2 interacting domain of yeast pcf11 (PDB code 1SZ9), a protein involved in polyadenylation-dependent 3'-mRNA processing (10). 
Table S1. Structure homologies among the HEAT domains of eIF4G and CBP80

\begin{tabular}{|l|c|c|c|l|l|l|l|}
\hline & $\begin{array}{l}\text { CBP80 } \\
\text { HEAT-1 }^{\text {a }}\end{array}$ & $\begin{array}{l}\text { CBP80 } \\
\text { HEAT-2 }\end{array}$ & $\begin{array}{l}\text { CBP80 } \\
\text { HEAT-3 }\end{array}$ & $\begin{array}{l}\text { 4G } \\
\text { HEAT-1 }\end{array}$ & $\begin{array}{l}\text { 4G } \\
\text { HEAT-2 }\end{array}$ & $\begin{array}{l}\text { 4G } \\
\text { HEAT-3 }\end{array}$ & $\begin{array}{l}\text { 2B } \boldsymbol{E} \\
\text { HEAT 3 }\end{array}$ \\
\hline CBP80 HEAT-1 & $39.9^{\text {b }}$ & & & & & & \\
\hline CBP80 HEAT-2 & 9.1 & 32.5 & & & & & \\
\hline CBP80 HEAT-3 & 5.9 & 6.8 & 38.6 & & & & \\
\hline 4G HEAT-1 & $\underline{\mathbf{1 3 . 2}}^{\text {c }}$ & 8.4 & 7.2 & 33.5 & & & \\
\hline 4G HEAT-2 & 9.0 & $\mathbf{1 0 . 9}$ & 8.0 & 9.8 & 37.0 & & \\
\hline 4G HEAT-3 & 5.4 & 6.0 & $\mathbf{1 4 . 2}$ & 7.1 & 8.7 & 28.9 & \\
\hline 2B $\boldsymbol{\varepsilon}$ HEAT 3 & 6.6 & 6.7 & $\mathbf{1 1 . 4}$ & 5.3 & 8.2 & $\underline{\mathbf{1 2 . 3}}$ & 32.7 \\
\hline
\end{tabular}

${ }^{a}$ HEAT-1, MIF4G domain; HEAT-2, MA-3 domain and the corresponding HEAT-2 domain in CBP80; HEAT-3, W2 domain and the corresponding HEAT-3 domain of CBP80; 4G, eIF4G;2B $\varepsilon$ HEAT 3 , W2 domain in eIF2B $\varepsilon$ homologous to the HEAT-3/W2 domain of eIF4G.

${ }^{\mathrm{b}} \mathrm{Z}$ scores from DALI (5). Scores higher than 2 are considered significant. Scores on the diagonal (grey) are reference values for the domain compared to itself.

${ }^{\mathrm{c}}$ Scores in bold underlined are for homologous domains; scores in bold are for corresponding domains in the eIF4G and CBP80 structures with no detectable sequence homology.

\section{Families of close eIF4G homologs}

The translation repressor NAT1/DAP5/p97 is homologous to the C-terminal two-thirds of eIF4G (17) and has the same three-HEAT domain arrangement. NAT1 is present in most Metazoa species (18). Based on sequence homology, NAT1 appears to have diverged from eIF4G before the separation of Metazoa from fungi and plants (19), although sequence conservation alone is not a very reliable criterion. However, NAT1 must have existed at least early in Metazoan evolution, since it is present in both insects and vertebrates (18). NAT1 is not found in nematodes, which appears to correlate with the loss of the HEAT-3/W2 domain from nematode eIF4G (see above).

The HEAT-3/W2 domain of eIF4G is a close homolog of the HEAT/W2 domains of eIF2B $\varepsilon$ and eIF5 (Fig. $1 B)$. In view of the evidence about the origin of eIF4G presented here, one can conclude that the W2 domains of eIF2B $\varepsilon$ and eIF5 were products of gene duplication of the W2 domain of eIF4G. They are homologous to the eIF4G HEAT-3/W2 domain, but not to the HEAT-3 domain of CBP80, and therefore must have diverged from the eIF4G W2 domain after eIF4G had diverged from CBP80. We also found that a family of proteins previously reported to have a W2 domain (8) contain consecutive HEAT-2/MA3 and HEAT-3/W2 domains, but not a HEAT-1/MIF4G domain. The members of this protein family are often annotated in the databases as "Basic leucine zipper and W2 domain containing", where the helical HEAT-2/MA3 domain is mislabeled as basic leucine zipper. The source of the "basic leucine zipper" annotation is not clear, since the only detectable homologs of this family of proteins are the HEAT-3/W2 domains of eIF5 and eIF2B $\varepsilon$ and the HEAT-2/MA3 and HEAT-3/W2 domains of eIF4G. There is also no mention of a "basic leucine zipper" in the paper that first reported the presence of a W2 domain in this family (8). Since the proteins show clear homology with the HEAT-2/MA3 domain of eIF4G ( $\sim 20 \%$ identity and $\sim 35 \%$ conservation $)$ and their sequences start exactly at the predicted N-terminus of the HEAT-2/MA3 domain (not shown), we propose the name for these proteins to be "MA3+W2". The observed sequence homology to the HEAT-2/MA3 and HEAT-3/W2 domains indicates that this MA3+W2 protein family is derived from eIF4G. Members of the MA3+W2 protein family were identified in virtually all eukaryotic genomes (the accession number for the two human isoforms are EAL24285 and AAH26303), including one of the most primitive eukaryotes, Giardia lamblia (accession number EAA40087). Therefore, this family must have branched out of eIF4G very early in eukaryotic evolution. The W2 domain 
sequence of the MA3+W2 family is closely related to those of the eIF5 and eIF2B $\varepsilon$ HEAT/W2 domains, indicating that they may have evolved from a common ancestor more recently, after branching apart from eIF4G. It was suggested that this family of proteins could be a translation regulator, e.g., through modulation of the interactions of eIF5, eIF2B $\varepsilon$ and eIF4G (8). The finding that these proteins contain not only a HEAT-3/W2 domain, but also a HEAT-2/MA3 domain provides further support for this hypothesis.

\section{Conserved peptides in eIF4G that could interact with the HEAT domains}

Sequence analysis revealed the existence of three conserved peptides near the HEAT-1/MIF4G domain of eIF4G (see Fig. 1A and Fig. S1C and D). The first one is located N-terminal from the HEAT-1/MIF4G domain and we designate it as H1-NT. It is conserved in virtually all analyzed eIF4G sequences, as well as in NAT1. The eIF4G homolog PAIP1, which contains only a HEAT-1/MIF4G domain (20), has a conserved peptide at the same location. This conserved PAIP1 peptide is known as PAM-2 motif and was reported to bind to the Cterminal domain of PABP (PABC). PAM-1 and -2 peptides bind to the N-terminal RRM domains and the Cterminal domain of PABP, respectively (21). Whereas eIF4G binds to the N-terminal RRM domains of PABP1 through a peptide near its N-terminus, it does not have a PAM-2 motif and does not interact with the PABC. Not only the position with respect to the MIF4G domain, but also the sequences of the H1-NT and the PAM-2 peptides are similar, suggesting that they have a common origin but have evolved to interact with different partners.

The second conserved eIF4G peptide is found C-terminal from the HEAT-1/MIF4G domain and is designated here H1-CT. This peptide was part of the eIF4G fragment resistant to limited proteolysis, which was used for structure determination of the HEAT-1/MIF4G domain from human eIF4G2. However, the peptide was not part of the HEAT domain and was disordered in the crystal structure (10). H1-CT is conserved in all eIF4G homologs, including NAT1, and even between eIF4G and CBP80. The corresponding region of CBP80 wraps around the HEAT-1 domain (12), and therefore the same is probably true for the H1-CT peptide of eIF4G. The conservation among vertebrate eIF4G sequences extends even further (Fig. S1D), indicating that the linker could wrap at least halfway around the HEAT-1/MIF4G domain of eIF4G. Additional segments of the linker between the first two HEAT domains are highly conserved among vertebrate eIF4Gs, but the conservation is marginal at best with fungal eIF4Gs (especially those fungal eIF4G sequences that do not have the HEAT2/MA3 domain, (Fig. S1D)). There is no obvious conservation of this linker region between eIF4G and NAT1.

The third conserved peptide is found at the C-terminus of yeast eIF4G and in a similar position in the linker between the first and second HEAT domains of human eIF4G, and is designated here y4G-CT. It can be found in most eIF4G sequences, but not in NAT1 (Fig. S1D) or CBP80 (not shown). Peptides located at the Cterminus of a protein can easily be lost in evolution (through introduction of a stop codon), which suggests that there has been selective pressure for retention of $\mathrm{y} 4 \mathrm{G}-\mathrm{CT}$.

\section{References}

1. $\quad$ Altschul, S. F., Madden, T. L., Schaffer, A. A., Zhang, J., Zhang, Z., Miller, W., and Lipman, D. J. (1997) Gapped BLAST and PSI-BLAST: a new generation of protein database search programs, Nucleic Acids Res 25, 3389-402.

2. McGinnis, S., and Madden, T. L. (2004) BLAST: at the core of a powerful and diverse set of sequence analysis tools, Nucleic Acids Res 32, W20-5.

3. Notredame, C., Higgins, D. G., and Heringa, J. (2000) T-Coffee: A novel method for fast and accurate multiple sequence alignment, $J$ Mol Biol 302, 205-17.

4. Thompson, J. D., Higgins, D. G., and Gibson, T. J. (1994) CLUSTAL W: improving the sensitivity of progressive multiple sequence alignment through sequence weighting, position-specific gap penalties and weight matrix choice, Nucleic Acids Res 22, 4673-80.

5. Holm, L., and Sander, C. (1993) Protein structure comparison by alignment of distance matrices, $J$ Mol Biol 233, 123-38. 
6. Koradi, R., Billeter, M., and Wuthrich, K. (1996) MOLMOL: a program for display and analysis of macromolecular structures, J Mol Graph 14, 51-5, 29-32.

7. Koonin, E. V. (1995) Multidomain organization of eukaryotic guanine nucleotide exchange translation initiation factor eIF-2B subunits revealed by analysis of conserved sequence motifs, Protein Sci 4, 160817.

8. Aravind, L., and Koonin, E. V. (2000) Eukaryote-specific domains in translation initiation factors: implications for translation regulation and evolution of the translation system, Genome Res 10, 1172-84.

9. Ponting, C. P. (2000) Novel eIF4G domain homologues linking mRNA translation with nonsensemediated mRNA decay, Trends Biochem Sci 25, 423-6.

10. Marcotrigiano, J., Lomakin, I. B., Sonenberg, N., Pestova, T. V., Hellen, C. U., and Burley, S. K. (2001) A conserved HEAT domain within eIF4G directs assembly of the translation initiation machinery, Mol Cell 7, 193-203.

11. Dhalia, R., Reis, C. R., Freire, E. R., Rocha, P. O., Katz, R., Muniz, J. R., Standart, N., and de Melo Neto, O. P. (2005) Translation initiation in Leishmania major: characterisation of multiple eIF4F subunit homologues, Mol Biochem Parasitol 140, 23-41.

12. Mazza, C., Ohno, M., Segref, A., Mattaj, I. W., and Cusack, S. (2001) Crystal structure of the human nuclear cap binding complex, Mol Cell 8, 383-96.

13. Mazza, C., Segref, A., Mattaj, I. W., and Cusack, S. (2002) Large-scale induced fit recognition of an $\mathrm{m}(7) \mathrm{GpppG}$ cap analogue by the human nuclear cap-binding complex, EMBO J 21, 5548-57.

14. Calero, G., Wilson, K. F., Ly, T., Rios-Steiner, J. L., Clardy, J. C., and Cerione, R. A. (2002) Structural basis of $\mathrm{m} 7 \mathrm{GpppG}$ binding to the nuclear cap-binding protein complex, Nature Struct Biol 9, 912-7.

15. Cingolani, G., Petosa, C., Weis, K., and Muller, C. W. (1999) Structure of importin-beta bound to the IBB domain of importin-alpha, Nature 399, 221-9.

16. Meinhart, A., and Cramer, P. (2004) Recognition of RNA polymerase II carboxy-terminal domain by 3'RNA-processing factors, Nature 430, 223-6.

17. Imataka, H., Olsen, H. S., and Sonenberg, N. (1997) A new translational regulator with homology to eukaryotic translation initiation factor $4 \mathrm{G}$, EMBO J 16, 817-25.

18. Takahashi, K., Maruyama, M., Tokuzawa, Y., Murakami, M., Oda, Y., Yoshikane, N., Makabe, K. W., Ichisaka, T., and Yamanaka, S. (2005) Evolutionarily conserved non-AUG translation initiation in NAT1/p97/DAP5 (EIF4G2), Genomics 85, 360-71.

19. Hernandez, G., and Vazquez-Pianzola, P. (2005) Functional diversity of the eukaryotic translation initiation factors belonging to eIF4 families, Mech Dev 122, 865-76.

20. Craig, A. W., Haghighat, A., Yu, A. T., and Sonenberg, N. (1998) Interaction of polyadenylate-binding protein with the eIF4G homologue PAIP enhances translation, Nature 392, 520-3.

21. Roy, G., De Crescenzo, G., Khaleghpour, K., Kahvejian, A., O'Connor-McCourt, M., and Sonenberg, N. (2002) Paip1 interacts with poly(A) binding protein through two independent binding motifs, Mol Cell Biol 22, 3769-82.

22. Boesen, T., Mohammad, S. S., Pavitt, G. D., and Andersen, G. R. (2004) Structure of the catalytic fragment of translation initiation factor $2 \mathrm{~B}$ and identification of a critically important catalytic residue, $J$ Biol Chem 279, 10584-92.

\section{Figure legends}

Fig. S1 Structure-based sequence alignment of selected vertebrate eIF4G, NAT1 and CBP80 homologs A. HEAT-1/MIF4G domain and H1-CT peptide. Residues identical in $\geq 80 \%$ of the sequences are in red; residues conserved in $\geq 80 \%$ of the sequences are in blue; and residues that are hydrophobic in $\geq 80 \%$ of the sequences are in light blue. The location of the H1-CT peptide (C-terminal from the HEAT-1/MIF4G domain) is marked. Abbreviations: XENLA, Xenopus laevis; XENTR, Xenopus tropicalis; DANRE, Danio rerio; TETNI, Tetraodon nigroviridis. 
B. HEAT-2/MA3 and HEAT-3/W2 domains. Coloring and abbreviations are as in panel (A). C-terminal ends of sequences are labeled with "*".

C. Sequence alignment of the H1-NT peptide of eIF4G between vertebrates and fungi. The location of the H1NT peptide (N-terminal from the HEAT-1/MIF4G domain) is marked. The N-terminal segment of the HEAT1/MIF4G domain is included as a reference for the location and the degree of sequence conservation of the H1NT peptide. Coloring is as in panel $(\boldsymbol{A})$, but the fungal eIF4G sequences are colored only if conserved with the vertebrate eIF4G sequences. A sequence alignment of the corresponding region of the PABP-interacting protein 1 (PAIP1) is also shown, in order to illustrate the similar location and degree of conservation between the H1NT peptide in eIF4G and the PABP-interacting motif 2 (PAM-2) peptide in PAIP1, which binds to the Cterminal domain of PABP. Abbreviations are as in panel (A). 4G_CRYNE1 and 2, Cryptococcus neoformans strain 3501A eIF4G isoforms 1 and 2; USTMA, Ustilago maydis; MAGGR, Magnaporte grisea; GIBZE, Gibberella zeae; SCHPO, Schisosaccharomyces pombe; 4G_YEAST1 and 2, Saccharomyces cerevisiae eIF4G isoforms 1 and 2.

D. Sequence alignment of the H1-CT and y4G-CT peptides of eIF4G between vertebrates and fungi. The locations of the H1-CT peptide (C-terminal from the HEAT-1/MIF4G domain) and the y4G-CT (at the Cterminus of yeast eIF4G) are marked. Coloring and abbreviations are as in panel $(\boldsymbol{C})$. Sequence segments in italic were not aligned. "*", C-terminal end of sequence. Provisional eIF4G sequences derived from unfinished fungal genomes are labeled with "p" at the end of the name. CnH99, Cryptococcus neoformans strain H99; CnR265, Cryptococcus neoformans strain R265, COPCI, Coprinopsis cinerea.

E. Sequence alignment of human eIF4H, eIF4B and CBP20. Coloring is as in panel $(\boldsymbol{A})$, except the threshold for coloring is $66 \%$, because there are only three sequences. The residue numbers at the beginning and end of the alignment, as well as the total length of the proteins, are indicated. C-terminal ends of sequences are labeled with "*". The pairwise sequence homologies for the aligned region are: eIF4B:eIF4H - 31\% identity and 46\% homology; eIF4B:CBP20 - 18\% identity and 27\% homology, and eIF4H:CBP20 - 27\% identity and 37\% homology. For comparison, the homology between the HEAT-1/MIF4G domains of eIF4G and CBP80 (the only regions where sequence homology is detectable) is $10 \%$ identity and $29 \%$ homology.

\section{Fig. S2 Conservation of domain surfaces among eIF4G and NAT1 homologs}

A. The eIF4G HEAT domains in surface representation, oriented by aligning them to the corresponding HEAT domains of CBP80 from the CBP80:CBP20 complex, PDB code 1HT2 (13). The eIF4G2 HEAT-1/MIF4G domain is from PDB entry 1HU3 (10); the HEAT-2/MA3 and HEAT-3/W2 domains are from PDB entry 1UG3 (S. Burley, unpublished). Note that the resulting orientation of the HEAT-2/MA3 and HEAT-3/W2 domains differs from that observed in PDB entry 1UG3. The linker between the HEAT-1 and HEAT-2 domains of CBP80 is shown for reference, since the corresponding region in eIF4G could have a similar (but not necessarily identical) location. The surfaces are painted by sequence conservation between the vertebrate eIF4G and NAT1 homologs shown in Fig. S1A and B. Residues identical in $\geq 80 \%$ of the sequences are colored red; residues conserved in $\geq 80 \%$ of the sequences are colored violet; residues hydrophobic in $\geq 80 \%$ of the sequences are colored yellow. The structure in $1 \mathrm{UG} 3$ has a $\mathrm{C}$-terminal deletion of 34 residues, which was modeled here using the corresponding region in the structure of the homologous W2 domain from eIF2B $\varepsilon$, PDB code $1 \mathrm{PAQ}$ (22).

B. Same as in panel $(\boldsymbol{A})$, but the HEAT-2/MA3 domain is in ribbon representation, in order to display the predicted contact surfaces on the HEAT-1/MIF4G and HEAT-3/W2 domains. The surface of the HEAT-3/W2 domain that contacts the HEAT-2/MA3 domain in PDB entry 1UG3 is indicated with an arrow.

C. Same as in panel $(\boldsymbol{A})$, but the HEAT-1/MIF4G and HEAT3/W2 domains are in ribbon representation, in order to display the predicted contact surfaces on the HEAT-2/MA3 domain. The surface of the HEAT-2/MA3 domain that contacts the HEAT-3/W2 domain in PDB entry 1UG3 is indicated with an arrow. 


\section{Fig. S1. Structure-based sequence alignment of selected vertebrate eIF4G, NAT1 and CBP80 homologs A. HEAT-1/MIF4G domain and H1-CT peptide}

4G1_HUMAN 4G1_MOUSE 4G1_RAT 4G1_TETNI $4 G 2$ HUMAN 4G2_MOUSE $4 \mathrm{G} 2$ HORSE 4G2_TETNI NAT 1 HUMAN NAT1_MOUSE NAT1 RABIT NAT1 XENLA NAT 1 XENTR NAT1_DANRE NAT1 TETNI CBP8CBP8_MOU CBP80_RAT CBP80_DOG CBP80_CHICK CBP80_XENLA CBP80 XENTR consensus

4G1 HUMAN 4G1 MOUSE 4G1_RAT 4G1 TETNI 4G2_HUMAN 4G2_MOUSE 4G2 HORSE 4G2 TETNI NAT'1_HUMAN NAT1 MOUSE NAT 1 RABIT NAT1 XENLA AAT_ XENTR NAT1_DANRE NAT1 TETNI CBP80_HUMAN CBP80_MOUSE CBP80-RAT CBP80 DOG

CBP80_CHICK CBP80 XENTR consensus

EEDADGSKTQDLFRRVRS ILNKLT----PQMFQQLMKQ TQLA DTEERLKGVIDLI EKAISEPNFSVAYANM CYANM RCLMALKVPTTEKP-------TVTVNFRKL LNR QKE F EEDADGSKTODI RRVRSILNKLT----POMFOOLMKO TOLA IDTEERLKGVIDLI EKAISE PNFSV YANM CYANM RCLMALKVPTTEKP-------TVTVNFRKL LNR OKE E FDADG ENDPEMIKTTELLFRVRS ILNKLT----POKFOOLMKO MELN DTEERLKGVIDLI EKAISE PNFSV YANMCYANM RCLIGLRVDISDKM-------GATVNFRKV LLNR CKE E ADDPENIKTOEL RKVRSILNKLT----POMFNOLMKO SGLT VDTEERLKGVIDLV EKAIDEPSFSV YANM YANMCRCLVTLKVPMADKP-------GNTVNFRKL LNR OKE E ADDPESIKTOEL FRKVSILNKLT----POMFNOLMKO SALT AEDPENIKTOELFRKVR ILNKLT----POMFNQLMKO SGLTVDTEERLKGVIDLV EKAIDEPSFSV YANMCYANM RCLVTLKVPMADKP--------GNTVNFRKL LNR OKE E ADDPEVLKTOELFRKVRS ILNKLT----POKFNOLMRO SGLT DTEERLKGVIDLV EKAIDEPSF VAYANM YANM RCLVTLKVPMADKP-D NSANEKERHDAIRRKVRILNKT----PEKFDKLI I NSANEKERHDAIFRKVGILNKLT----PEKFDKLCLE LNVG ESKLILKGVILIVALE E NSANEKERHDAIFRKVRGILNKLT----PEKFDKLCLE LNVGVESKLILKGVILLIVDKALEEPKYSS $\triangle Y A Q L C Y A Q L C L L A E D A P N F D G P A A E G Q P G Q K Q S T$ TFRRL ISK QDE E SSSSEKERHDAIFRKVRGILNKLA----PEKFDKLCLE LNVGVDSLILKGVILLIVDKALEEPKYSS $\triangle Y A Q L C Y A Q L$ LRLAEDAPNFDGPSADGPPGQKOS TTFRRL ISK ODE E ISSSEKERHDAIFRKVRGILNKLA----PEKFDKLCLE LLNVG DTKLILKGVILLIVDKALEEPKYSS $\triangle Y A Q L C Y A Q L C L R L A E E A P N F D G P S T D G Q P G Q K Q S T T F R R I I S K \perp Q D E$ E NSSNEKERHAT NSYNEKGQHDAIFRKVRSILNKLT-D-PEKFDKLCLE LN

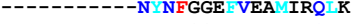
HKRRKTSDANE EDHLESLICKVGEKSACSLESNLEGL GVLE DLPNYKSKILRLLCTVARLLPEKLT IYTTLVYTL GLLNAR--

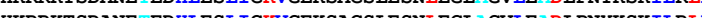
HKRRKTSDANE EDHLESLICKVGEKSACSLESNLEGL GVLE DLPNYKSKILRLL TVARLLPEKLT I YTTLVYTTL GLLNAR-HKRRRT SEPSE IEERLESLICRVGEKSNSSLESNLEGL GVLE $\triangle$ DLPNYKSKILRIL TVARLLPEKLTVYTTLVYTTL VGLINAR----1 HKRRRT SEPLE IEDRLESLICRVGEKSTSSLESNLEGL GVLE DLPNYKNKILRIL FVARLLPEKMTVYTTLVYTTL GLLNAR---1

KDKDDDEVFEKKOKEMDEAATAEERGRLKEELEEARDIARRRSLGNIKFIGELFK KMLTEAIMHD CVVK LKN----------HDEESLECLCRLLTTIGKDLDFEKAKPRMDQYFNQ KDKDDDVVEKKOKE KDKDDEVFEKR KDKDDDEIIERKRKDLESASE-DEKORLVEELOEAEDTARRRSLGNIKFIGELFK KMLTEVIMHD CIVK LKN-------HDEESLECLCRLLSTIGKDLDFEKAKPRMDQ $Y$ FNQ KDKADDDVFEKKQKELEAASAPEERTRLHDELEEAKDKARRRS I GNIKFIGELFK KMLTEAIMHD CVVK LKN--------HDEESLEC CRLITTIGKDLDFEKAKPRMDQY FNQ KDKADDDVFEKKQKELEAASAPEERTRLHDELEEAKDKARRRS I GNIKFIGELFK KMLTEAIMHD CVVK LKN-------HDEESLEC $L C R L L T T I G K D L D F E K A K P R M D Q Y F N Q$ E KDKADDDVFEKKQKEFEAASAPEERTRLHDELEEAKDRARRRS IGNIKFIGELFK KMLTEAIMHD CVVK LKN--------HDEESLGCLCRLLTTIGKDLDFEKAKPRMDQ $Y$ FNQ E KDKVDDVVFERRQKELDSTASTTERERLQEELEEAKDKARRRS IGNIKFIGELFK KMLTEAIMHD CVVK LKN--------HDEESLEC $L C R L L T T I G K D L D F E K A K P R M D Q Y$ FNQ $E$ NRTRNVD--------VYDKRENPLLPEEEEQRAIAKIKMLGNIKFIGELGK DLIHESILHK $I K T$ LEKKK--RVQLKDMGEDLEC $\triangle Q$ QIMRTVGPRLDHERAKSLMDQYFAR C NRTRNVD----------VYDKRENPLLPEEEEORAIAKIKMLGNIKFIGELGK DLIHESILHKCIKT LEKKK--RVQLKDMGEDLEC LCOIMRTVGPRLDHERAKSLMDQYFAR C NRTRNVD---------VYDKRENPLLPEEEEORAIAKIKMLGNIKFIGELGK DLIHESILHKC $I$ KT LEKKK--RVQLQDMGEDLEC $\triangle$ CQIMRTVGPRLDHERAKSLMDQYFAR C TRSRIVENRRVE

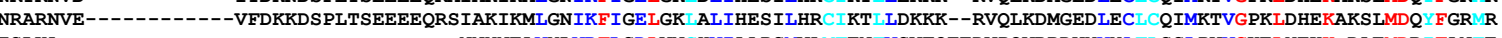
ESLKA----ESLKA--ESLKA---ESLKA--ECLKV----

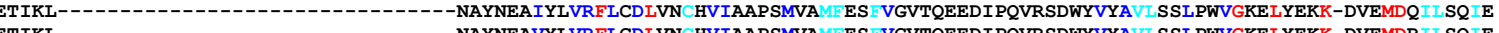

\section{End of HEAT-1/MIF4G domain 7 H1-CT}

\urcorner End of proteolysis-resistant fragment of human eIF4G2

4G1_HUMAN 4G1_MOUSE 4G1_RAT 4G1 TETNI 4G1_TETNI 4G2 MUUSE 4G2 2 HORSE 4G2 - HORSE 4G2 TETNI NAT'1_HUMAN NAT1 RABIT NAT1 XENLA NAT1 XENTR NAT1_DANRE NAT1 TETNI CBP80_HUMAN CBP80_MOUSE CBP80_RAT CBP80_DOG CBP80_CHICK CBP80_XENLA CBP80_XENTR consensus

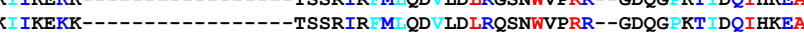 -TSSRIR M QDVLDLRGSNWVRR--GDQG $P$ KTIDQIHKE KI IKEKK--------------TSSRIR $M$ QD VLDLRQSNWVPRR--GDQG $P$ KT IDQIHKEA

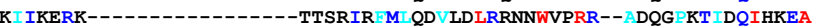

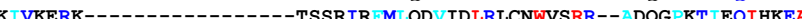 KIVKERK----------------TSSRIR $M$ M OD IDLRLCNWVSRR-- $D$ DQ TKT TEOIHKE KIVKERK--------------TSFRIR M QDVIDLRLCNWVSRR-- DOG $R T$ T EQIHKE KIVKERK------------TSSRIR M QD I IDLRLHNWVSRR-- ADQG $R$ KT IEQIHKE

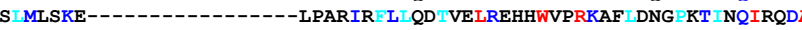

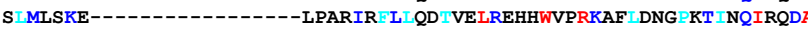 S I MLSKE-----------LPARIR L LD IVELREHHWVRKAF DNG $P K T I N Q I R Q D$ AI KANKE---------LPARIR L QD TMELRANNWAPRTAFNDNG KT ITQIRHDA

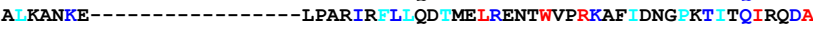 S MNNKD-------------LPARIR L QD VELRENNWVRKAF DNG $P K T \perp N Q I R Q D A$

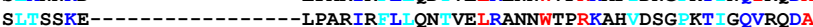 S LKRROKTHVPMLOVWTADKPHPOEEYLD L AO OKLKKDRWOERH-- LRP LA DS ILCEA SYIKRROKTHVPMLOVWTADKPHPOEEYLD C IAO OKLKKDRWOERH-- IRPYIA DSILCEA S $Y$ LKRRQKTHVPMLQVWTADKPHPQEEYLD L I AQ QKLKKDRWQERH-- ILRPYLA DSILCE S LKRRQKTHVPMLQVWTADKPHPQEEYLD L AQ QKLKKDRWQERH-- LRP LA DS I LCEA

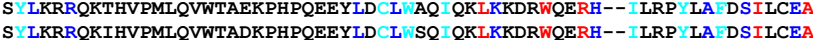 S $Y$ LKRRQKIHVPMLQVWTADKPHPQEEYLD $C$ SQ QKLKKDRWQERH-- ILRP YLA DSILCEA

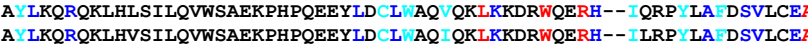




\section{B. HEAT-2/MA3 and HEAT-3/W2 domains}

4G1_HUMAN 4G1 MOUSE 4G1 RAT 4G1_TETNI $4 G 2$ HUMAN $4 \mathrm{G} 2$ HUMAN $4 \mathrm{G} 2$ MOUSE G2_HORSE 4G2 TETNI NAT1_HUMAN NAT1_RABIT NAT1_XENLA NAT1 XENTR NAT1 DANRE NAT1 1 TETNI CBP80 0 HUMAN CBP80 MOUSE CBP80_RAT CBP80 DOG CBP80_CHICK CBP80_XENLA CBP80_XENTR
consensus

4G1_HUMAN 4G1_MOUSE 4G1_RAT 4G1_TETN $4 G 2$ HUMAN 4G2 MOUS 4G2 HORSE 4G2 TETNI NAT1_HUMAN NAT1_MOUSE NAT1_RABIT NAT1_XENLA NAT1_XENTR NAT1_DANRE NAT1_TETNI CBP80_HUMAN CBP80_MOUSE CBP80 RAT CBP80-DOG CBP80_CHICK CBP80_XENLA CBP80_XENTR consensus

4G1_HUMAN 4G1 MOUSE 4G1_RAT 4G1 TETNI 4G2 HUMAN 4G2 HUMAN 4G2 2 HORSE 4G2_HORS 4G2 TETNI NAT1_HUMAN NAT1_MOUSE NAT1_RABIT NAT1_XENLA NAT1 DANRE NAT1 TETNI CBP 80 HUMAN CBP80 MOUS CBP80 RAT CBP80-RAT CBP80-CHICK CBP80 XENLA CBP80 XENTR CBP80_XEN'R
consensus
KAA SEEELEKKSKAI IEEY IHLNDMKEAVQCVQE L---ASPS LFI VRHG EST TERS--AIAREH GQLLHQLLCAG-HLSTAQYYQGLYEIIEL EDMEIDI H WLY LAE IVTPI

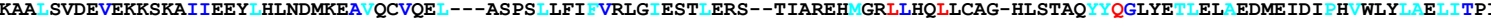

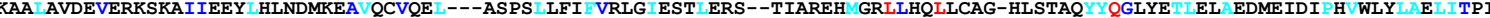

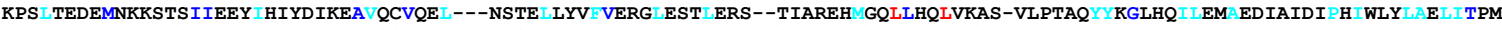

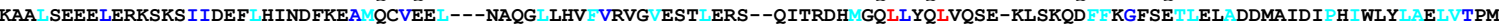

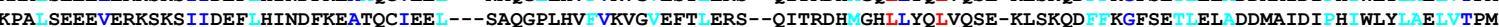
KPT SEEEMERKSKSIIDEF HINDFKEA OCVEE ---NAOG LHV VRMG EST ERS--QITRDH GQLLYQLVRS-KLSKODFKGFSETEL DDMAIDI H TWLYAELVTPM

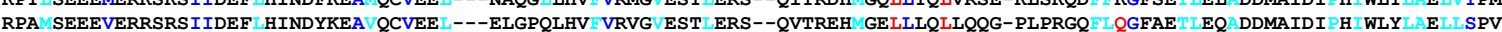

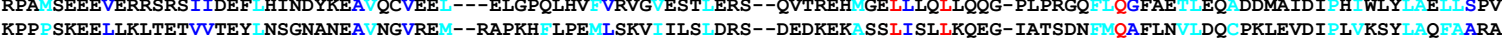

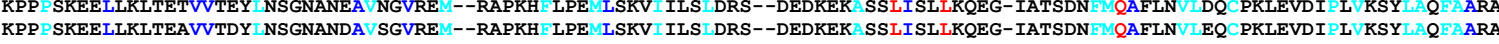

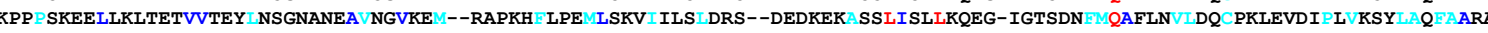

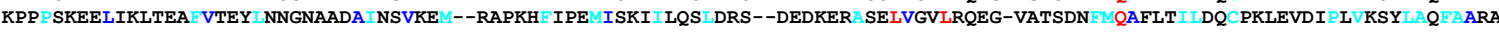
KPP SKEELIKLTEA VTEY NNGNAADA NSVKEM--RAPKH IPE ISKI IQS DRS--DEDKEK SALLGILRQEG-VATSDN EMAFLNIDQ PKLEVDI L KSY $I A$ Q ARA

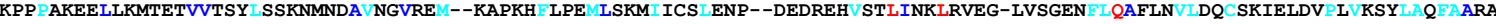

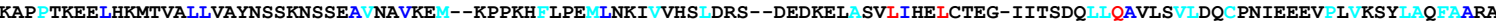
SHS VRFVIEENLHCIIKSH KE--RKTC AOLVS PGKNKIP NYH VEVI AEL OLPAPPHIDVM TTLLIELCKLOPGSLPOV AOATEM MR DT---MN T VDR TN SHH SHS TRFVIEVNLHCIIKSY ST

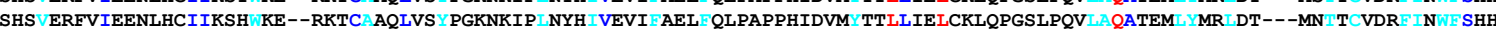

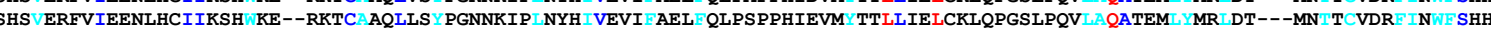
SHS ERFVIEENLHCILKSH RE--RKTC AQLLS PEKNKIP NYH VEVI GEL QLPSPQIDVM TTLLIELCKLQPGSLPQVLAQASEM TR DT---MN T TCIDR IN NE SH

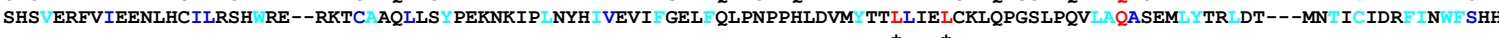

End of HEAT-2/MA3

¿Start of HEAT-3/W2

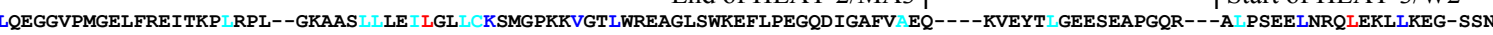
LQEDGVPMGELFRE ITKP $\perp$ RPM--GKATS $\perp$ LE ILGLCKSMGPKKVGMLWREAGLSWREFLAEGQDVGSFV EK----KVEYT GEESEAPGQR---T AFEELRRQLEKLLKDG-GSN

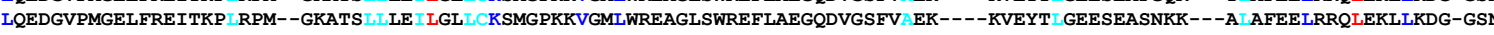
LHESGIQMGE LFREISKP IPL--GKAGV $L I V Q I L V L I C K E M S H K K$ GMMWREAGLRWKDFLPEDEDVNKFVTEK----SVEFT GDETEKSEALSKKE SSAELTKQLEKLIRDQ-ADN LKEGGISMRELTIEFSKP ILPV--GRAGVIISE ILHL $I C K Q M S H K K V G A L W R E A D L S W K D F L P E G E D V H N F L I E Q----K L D F I E S D S P C S S E A L S K K E I S A E E L Y K R L E K L I I E D K A N D$ LKEGGISMRELIVEFSKP LIPV--GRAGV LISE ILHL $\triangle$ RQMSHKKVGALWREADLSWKDFLPEGEDVHHFL EQ----KLDFTESEGPCSSEPLYKKE SAEELSQRLEKLIMEEKADD LKEGGISMRELIIEFSKP LPV--GRAGI I SE I LHL CKQMSHKKVGAVWREADLSWKDFLPEGEDVHSFL EQ----KLDFKKSDSSCSDAAPSKRE SAEELYKRLEKLIIEDKAND LKGGGF SMRELFSELRKA LPV--GKAGI I I SE I LHI ICKQMSQRTVASLWRESGLSWTDFLPEGEDVPTFITQQ----KLQFV $\triangle$ WDASGP-------L $\triangle S P E D L G Q Q L H R L L L E D V A S D$ II----SELVSISELAQ LES--GTHFP LF LL CLQQ A KLQDREWLTELFQQSKVNMQKMLPEIDQNKDRM EI----LEGKG SF----1 II-----SELVSISELAO LES--GTHFP LFL LLQQLAKLQDREWLTELFOQSKVNMQKMLPEIDQNKDRM EI----LEGKG SF------ L PLLKLEKELLKQIKLD-PSP II-----SELVSISELAQ LES--GTHFP LIL LL LQQ KLQDREWLTELFQQSKVNMQKMLPEIDQNKDRM EI----LEGKG SF-II-----AELVSLSELAQ LEN--GTLFP LILCLQQ KRLQDREWLTELFQQSKINMQKMLPEIDQNKDRM EI----LEGKG SF-II----AELVSLSELAQ LEN--GTLFP LFLLCLQQAKLQDREWLTELFQQSKINMQKMLPEIDQNKDRM EI----LEGKG SF-VI-----AELVSMAELAH LEN--GTHFP LF LL LLQQMAKLKDREWLTDLFQQSKVNMQKMLPEIDQNKDRM EI----LEGKG SF----------L PLMKLEKELLKQIKAD-PAP IN-----ADLVNLADLAHQLED--GAHFP LFL LI LQQ LMKLRGRDWLSDLFQQSKINMQKMLPEIDQKTDKM EI-----LEGKG SF----------L PLMKLEKELLKQIKVD-PSP LSNFQF--RWSWEDWSDC SQDPESPKPK FVR VLEK CMRLSYHQRILDI-----1

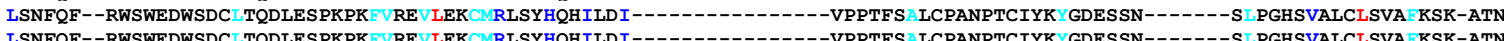

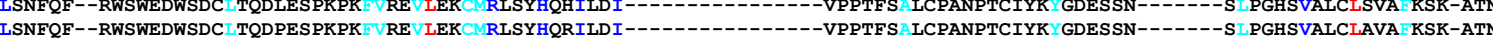
LSNFOF--RWSWEDWSDC TODIFKPKPK LNEQ LSNFQF--RWNWEDWSDC $\triangle$ SQDLDKPKPQ $F$ RE $V$ LEK CMRLSYHQRILDI-----------VPAAFS LYPASPSCVFK GDESNS-----A PGYSVAVALTNAIKNK-ASD

QRVFD IEAN S--------EQQIVSNTLVR MTAVCYS IIFE--------------TP RVDVAVLKARAKL QKYL-CDEQKELQ LY ILAL VTLEQPPNLLRM DA

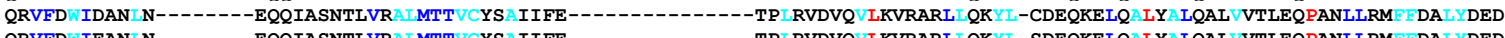
QRVFD IEAN N-------EQQIASNTLVR MTTVCYS IIFE-----------TP RVDVQ LKVRARL QKYL-SDEQKELQ IY IQAL VTLEQPANLLRM F DA Y DED

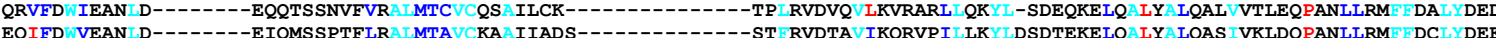
EQIFD WVAN D-------EIQMSSPTFLR MTAVCKA IIADS-ERIFD VEAN D-------ESQMSSPTFLR AIMTAVCKA IIADC-----4

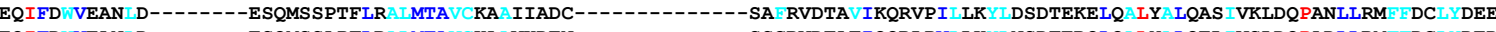
-SSCRVDTATIOORLPV LIKY NSDTERQLQ IY ALQEL IVSLDQPADLLRM F DC LYDED

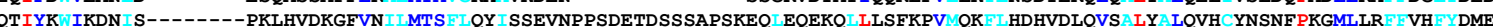

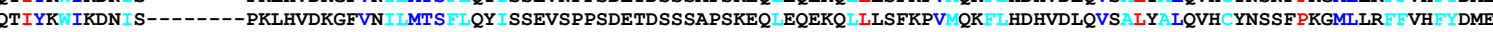

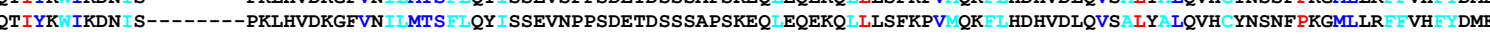
QTIYK IKDN $\triangle$ S--------PKLHLDKGFVNIIITS

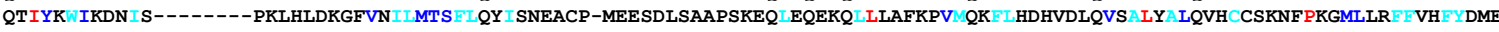

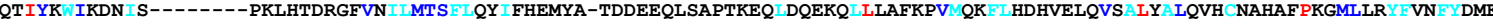
QSIYK IKEN S------ARLHTDKGFVN IITS QF LYEINP-DGDEEQLAAPSKEQ DEEKQLLSLKPV QK HDHTNLQVA LY LQVHCNGHSFPKGMLLR VY FYDME DEIFS ILKDV NPNQDDDDDEGF SFNPLKIE VIVQTLIHL A--------------KS SHSFS $\triangle$ LAKFHEV KT $\perp A-E S D E G K L H V L R \vee M F E V W R--N H P-Q M I A V L V D K M I R T Q$

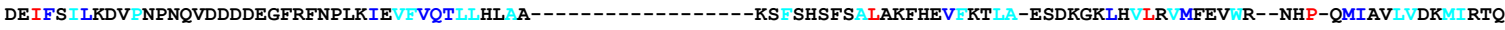

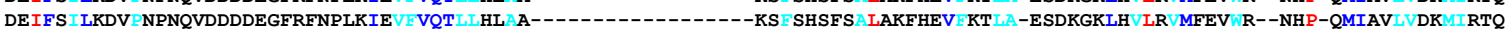

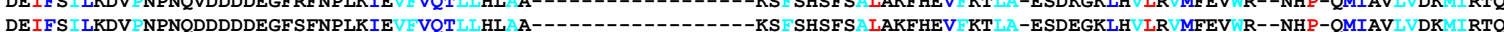
DEIFS LKDV NPNQDDDDDEGFTFNPLKIEVVOT T H A--KEIFN $I$ LKDI NPNQDDYDDEGIGFNPLKIE V VQTLINL S-KEIFN LKDI NPNQDDDDDEGISFNPLKIE VVQTLISL S------ VI

End of fragment used in 1UG3-

4G1 HUMAN VVKEDAFY SWESSKDPAEQOGKGVALKS TA FK LRE EEE-SDHN* 4G1 MOUSE VVKEDAFY SWESSKDPAEOGKGVALKS TA FN TRE EDEESDHN* 4G1 RAT VVKEDAFY SWESSKDPAEQOGKGVALKS TA FN LRE EDEESDHN* $4 G 1$ TETNI VIKEEAFYKWESSKDPAEQLGKGVALKS TA FTWLRE EDE-SDNS * 4G2 HUMAN VISEDAFYKWESSKDPAEONGKGVALKS TA FTWLRE EEE-SEDN * 4G2 MOUSE VISEDAFYKWESSKDPAEQAGKGVALKS TA FTWLRE EEE-SEDN* VISEDA KWESSKDPAEONGKGVALKS TA FTWLE EEE-SEDN* 4G2 TETNI VISEDAFYKWESSKDPAEQKGKGVALKS TA FT LRE EEE-SEDN* NAT 1 _HUMAN IIEEEAFT AWKEDITQ-EFPGKGKALFQ NQWTWLET AEEESEEEAD* NAT1 MOUSE IIEEEAFI AWKEDITQ-EFPGKGKALFQ NQ LTWLT IEEEESEEEAD* NAT1_RABIT IIEEEAFT AWKEDITO-EFPGKGKALFO NO LT LET EEEESEEEAD*

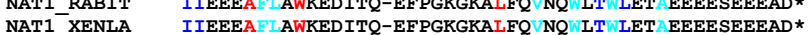

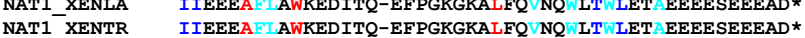
NAT1_XENTR IIEEA_ANEDITQ-EFPGKGKALFQ NQ LT LET EEEESEEEAD* NAT1_DANRE IIEEEAFIAWKEDITQ-EFPGKGKALFQ NQ LM LET EEEESEEEAD* $\begin{array}{ll}\text { NAT1 TETNI } & \text { IIEEEAFI SWKEDVTQ-EYPGKGKALFQ NQWLTWET EEEESDGED* } \\ \text { CBP8 } 0 \text { HUMAN } & \text { IVDCAAV NWIFSSELSRDFT---RLFV EI HST IRK NKHVLKIQKE }\end{array}$ CBP80-MOUSE IVDCAAVANWIFSSELSRDFT---RLFV EI HST IRK NKHVLKIQKE. . CBP80_RAT IVDCAAVANWIFSSELSRDFT---RLFVWEI HS IRK NKHVLKIQKE. CBP80_DOG IVDCAAVANWIFSSELSRDFT---RLFVWEI HS IRK NKHVLKIQKE. CBP80 CHICK IVDCAAVA NWIFSSELAHDFT---R YI EI HSTIRK NKHVLKIHKE. CBP80 XENLA IVDCAAVINWIFSPEISPDFT---R YI EITHSTIRK NKHVOKIOKE CBP80_XENTR IVDCAAVANWIFSPELSRDFP---R YIWEIIHSTIRK NKHVQKIQKE. consensus 


\section{Sequence alignment of the H1-NT peptide of eIF4G between vertebrates and fungi}

\section{H1-NT}

\begin{tabular}{|c|c|}
\hline & Гstart of HEAT-1/MIF4C \\
\hline 4G1_HUMAN & MTEDIKLNKAEKAWKPSSKR---TAADKDRGEEDADGSKTQDLFRRVRS \\
\hline 4G1_MOUSE & MTEDIKLNKAEKAWKPSSKR---TAADKDRGEEDADGSKTQDLFRRVRS \\
\hline 4G1_RAT & MTEDIKLNKAEKAWKPSSKR---TAADKDRGEEDADGSKTQDLFRRVRS \\
\hline 4G1-TETNI & LNDDVQLNKAEKAWKPSVKKSVRSRAAEEIDENDPEMIKTFELFKRVRS \\
\hline 4G2_HUMAN & VKEDVHLKKAENAWKPSQKR--------DSQADD PENIKTQELFRKVRS \\
\hline 4G2_MOUSE & VKEDVHLRKAENAWKPSQ̄KR--------DSHADD PESIKTQELFRKVRS \\
\hline 4G2_HORSE & VKEDVHLKKAENAWKPSQKR--------DIQAED PENIKTQELFRKVRS \\
\hline 4G2_TETNI & VNDDVQLKKSENAWKPGLKR---------ESSADD PEVLKTQELFRKVRS \\
\hline 4G_CRYNE1 & TPAA PIPISENAWTRKRLGGD--------------SEGTPAYIERKVKA \\
\hline 4G_CRYNE2 & ISAT PIPISENAWTRTRLGGD--------------AQGTPAYIERKVKA \\
\hline 4G_USTMA & 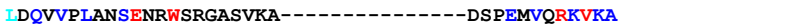 \\
\hline 4G_MAGGR & GMELKPIATTASGWKPMSLTKG-----APQNAGTGSHMEPEIVQRKVKA \\
\hline 4G_GIBZE & GMELKPIAQTATGWKPTSVGKA-----ASSTAPPSGHMEPDMVQRKVKA \\
\hline 4G_SCHPO & VDQVAPLQĨSANRWQPKKLTEK---PAETKGEDEEALLPPEVVQRRKVKG \\
\hline 4G_YEAST1 & KEEVAPLVPSANRWVPKFKSKK--TEKKLAPDGK ELLDKDEVERKMKS \\
\hline \multirow[t]{3}{*}{ 4G_YEAST2 } & KEEI PLVPSANRWI PKSRVKK--TEKKLAPDGK ELFDKEEVERKMKS \\
\hline & PAM2 \\
\hline & 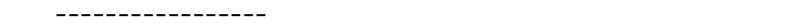 \\
\hline PIP1B_HUMAN & -VLRSKLSVNAPEFYPSGYSSSYTE---SYEVGCEDY---PT PEYVQD \\
\hline PIP1A_HUMAN & -VLMSKLSVNAPEFYPSGYSSSYTE---SYEDGCEDY---PTLSEYVQD \\
\hline PIP1_M̄MUSE & -VLMSKLSANAPEFYPSGYSSNYTE---SYEDGCEDY---PTLSEYVQD \\
\hline PIP1_DANRE & -VKNSKLSAAAAEFIPGGYSSVQDD---SYSDGSEGYYAEPSLADFVQD \\
\hline PIP1 TETNI & -VKPSTLSASAPEFVPTGMMYNNN---FYFDG-EDFYGEPSLADTVTE \\
\hline
\end{tabular}

\section{Sequence alignment of the H1-CT and y4G-CT peptides of eIF4G between vertebrates and fungi}

End of HEAT-1/MIF4G domain 7

${ }_{7}$ End of proteolysis-resistant fragment in human eIF4G2 H1-CT 4G1_HUMAN 4G1_RAT 4G1_TETNI $4 \mathrm{G} 2$ HUMAN 4G2_MOUSE $4 \mathrm{G} 2$ HORSE 4G2_TETNI

4G_CRYNE1 4G_CRYNE2 4G_USTMA 4G-CnH99-2p 4G-CnR265-1P 4G_COPCI_P TSSRIRFMLQDVLDLRGS-NWVPRR-GDQGPKTIDQIHKEAEMEEHREHIKVQQIM KGSDKRRGGPPGP

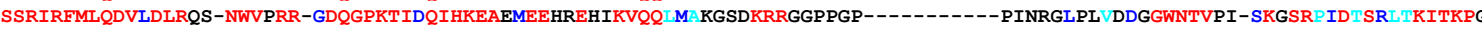
ISSRIRFMLQDVLDLRQS-NWVPRR-GDQGPKTIDQIHKEAEMEEHREHIKVQQIM KGGDKRRGGPPGP--------PVNRGLPL DDGGWNTVPI-SKGSRP IDISRITKITKPG TTSRIRFMLQDVLDLRRN-NWVPRR-ADQGPKTIDQIHKEAELEEHREHMKVQQ L SKKEMGGGPGGRMGGGGIGGRGGSHTPGRGGP QDEGWNTVPI-SK--RP ID PSR PKITKST TSSRIRFMLQDVIDLRLC-NWVSRR-ADQGPKTIEQI HKEAEIEEQEEQRKVQQIM KE--KRRPG-----------------VQR DEGGWNTVQG-AKNSRVIDP SKFIKITKP-

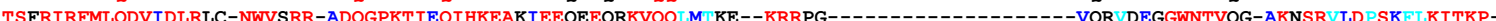
TSSRIRFMLQDI IDLRLH-NWVSRR-ADQGPKTIEQIHKEAKIEEQEEQRKVHQQLISKDSKRRPD-------------AREQRMQR--EETWNTVPM-TKNSRTID INKI PKISKP-

PSRIKFMIMDLNDLRRE-GWKSRK-NQSGVMTIAEIHEQNAKEKTAAA-A ARESISRGGSRSG-NRRDGT------------------QPGEWQSVS--SNPRSISR TTD SNIGRNI SSRIKFMIMDVE DLRRN-GWKSKK-NQTS MTIAQI HEQNAKEKSAASTAVSKES ISRGGSRSGRDRHEGS-----------------QPGEWQSVS--AGPRS NR TD TSNMGRNI

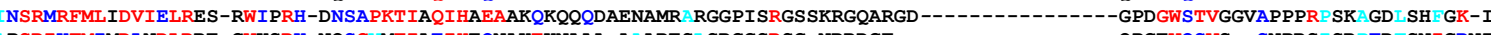

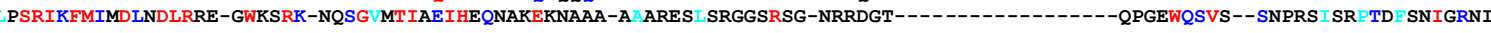

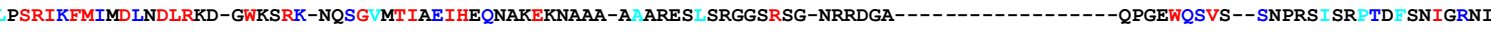
LSSRIKFMIMDVEDLRKN-GWKSKK-NQTS MTIAQIHEQNAKEKSAAA-TVTKD FISRGGSRSGRDRHEGS-------------QQPGEWQSVS--AGPRS INR PTD SNMGRNI VSPRMQFMLQVSNDLRER-KWVARN-AVAAPTTLAQVHQQAAKEAAQEKESMQR MT ---MSRTSSNRGRGRATDE-----------QPDGWAV G--SRPVS-TK GD ISN GK-I

4G_MAGGR 4G_GIBZE 4 G-YEAST1 4G_YEAST1

PSRLQFMLMDVVDLRKG-GWVSKE-ANKGPKTLDEVRAEAE AAAQKAAENAR-TNQRGGPRPPMGGRGSDMRG----------ISGYGQPQQNQNQVGMDDLRRLKGSAMRTSSONA PSRLKFMLLDVIDLRRA-KWVSKE-TNKGPKTLEEVRAEAE AQAAKAQE AR-TNQRGGGGPPVGRG-DARN---------FSGGYQQQAASNQVGMDDLRRLKGSANRTSSGNI PSRLKFMLLDVIDLRRA-KWVSKE-TNKGPKTLEEVRAEAE AQAAKAQE AR-TNQRGGGGRPVGRG-DARN--------FSGGYQQQAASNQVGMDDLRRLKGSANRTSSGNI SSRIKFKLIDIKELRHDKNWNSDK-KDNGPKTIQQIHEEEERQRQLKNNSRSNSRRTNNSSNRHSFRRDAPPASKD-ISSRIKFKLIDIKELRHDKNWNSDK-KDNGPKT IQQIHEEEERQRQLKNNSRSNSRRTNNSSNRHSFRRDAPPASKD------ SFITTRTYSQRNSQRAPP--
ISNRIKFKLIDVKELREIKHWNSAK-KDAGPKIQQIHQEEEQLRQKKNSQRSNSR NNHNQSNSNRYSSNRRNMQNT------QRDSFASTKTGSFRNNQRN-

4G1_HUMAN
4G1_MOUSE
4G1_RAT
4G1_TETNI
4G2_HUMAN
4G2_MOUSE
4G2_HORSE
4G2_TETNI
4G_CRYNE1
4G_CRYNE2
4G_USTMA
4G_CnH99-2t
4G_CnR265-1
4G_CnR265-2
4G_COPCI_t
4G_MAGGR
4G_GIBZE
4G_SCHPO
4G_YEAST1
4G_YEAST2

\section{y4G-CT}

SIDSNNQLFA PGGRL---SWGKGSSGGSGAKPSDAASEA----ARPATSTLNRFSALQQAVPTE. SIDSNNQL FA PGGRL----SWGKGSSGGSGAKPSDTASEA----TRPA--TLNRFSALQQTLPAE . . SIDSNNOL FA PGGRL---SWGKGSSGGSGAKPSDTASEA----TRPA--TLNRFSALOQTI PVE . . ALDFSNQYIA PGGKGTFGSWGKGSSGGTSTKPVDSGSEA---GTRPAASTLNRFSALQQ SSSS . . TIDEKIQLVPKAQLG---SWGKGSSGGAKASETDALRSS--------ASSLNRFSALQP PAPSG . . . TIDEKIQLVPKAQLG---SWGKGSSGGAKASETDALRSS--------ASSLNRFSALQP PAPSG . . . TIDEKIQLVPKAQLG---SWGKGSSGGAKASESDALRSS--------ASSLNRFSPLQPPAPSG. . QMDEKIQLG RAQV----TWVKGSSGGAKASDLELSRSA----------GLNRYSALQPTPPSQ . .

SSSSV---------TPSFGPSSVFANRKGKAATASNA-PSPTSR-PSS ANMFSALHE OESE . SSGGT--------APSFGPTSIFNTRKGKAGTPTNV-TPPMSRQPSS ANMFSALND QENE. . . RSSV-SSSSV-SSSSVSSGGT--------APSFGPTS IFNSRKGKAGTPTNI-TPPLSRQPSS ANMFSALND QEND . . SKAQPM-----------TFGPSSVFSKKDKRES-------LSR-SSSSSNMFSMLQN $Q$ E $\backslash N P$. . .

TFGPTSMFASRSNSGRA-RLGAGGPFGRAGEESGASSRTATPPTRESTSNANAFSLLANMETENPTSPPAVSPAMTKATPDTGDKDKK* SLGPASMLSSRSNSGR--RMGPGGFLGPRGEDSATSSRTGTPPTRENTSHSNAFSLLAN ENDHPASPPSTSASPAISKAVPADGDKKENE* GSHGPTSLSSMLKGGSVSRTPSRQNSALRREQS-----VRAPPSNVAVTSANSFE LLEEHDHDND GGQKDSNSKTSS * -PKEEPAAPTSTA NMFSATMGESDDFE* ARKVEEVSOAPR NMFDAT

\section{E. Sequence alignment of human eIF4H, eIF4B and CBP20}

4B_HUMAN 57 SNDDDVY--RAPPIDRSILPTAPRAAREPNIDRSRLPKSPPYTAFLGNLPYDVTEESIKEFF-RGLNISAVRLPREPSNPERIKGFGYAEFEDLDSLLSALSL-NEESLGNRRIRVDVADQ 4H_HUMAN 1 MADFDTYDDRAYSSFGGGRSRGSAGGHGSRSQKELPTEPPYTAYVGNLPFNTVQGDIDAIF-KDLSIRSVRLVRD-KD DKFKGFCYVEFDEVDSLKEALTY-DGALLGDRSLRVDIAEG CBP 20_HUMAN 1 M-SGGLKALRSDSYVELSQYRDQHFRGDNEEQEKLIKKS-CTLYVGNLSFYTTEEQIYELFSKSGDIKKIIMGLD-KMKKT CGFCFVEYYSRAD ENAMRYING RLDDRIIRTDWDAG

4B_HUMAN AQDKDRDDRSFGRDRNRDSDKTDTDWRARPATDSFDDYPPRRGDDSFGDKYRDRYDSDRYRDGYRDGYRDGPRRDMDRY 252 .. (611)* 4H_HUMAN ---RKQDKGGFGFRKG-----GPDDRG-MGS-SRES-------RGGWDSRDDFNSG-FRDDFLGG-RGG-SRPGDRR 175 ... (248) * CBP 20 HUMAN 
Fig. S2 Conservation of domain surfaces among eIF4G and NAT1 homologs
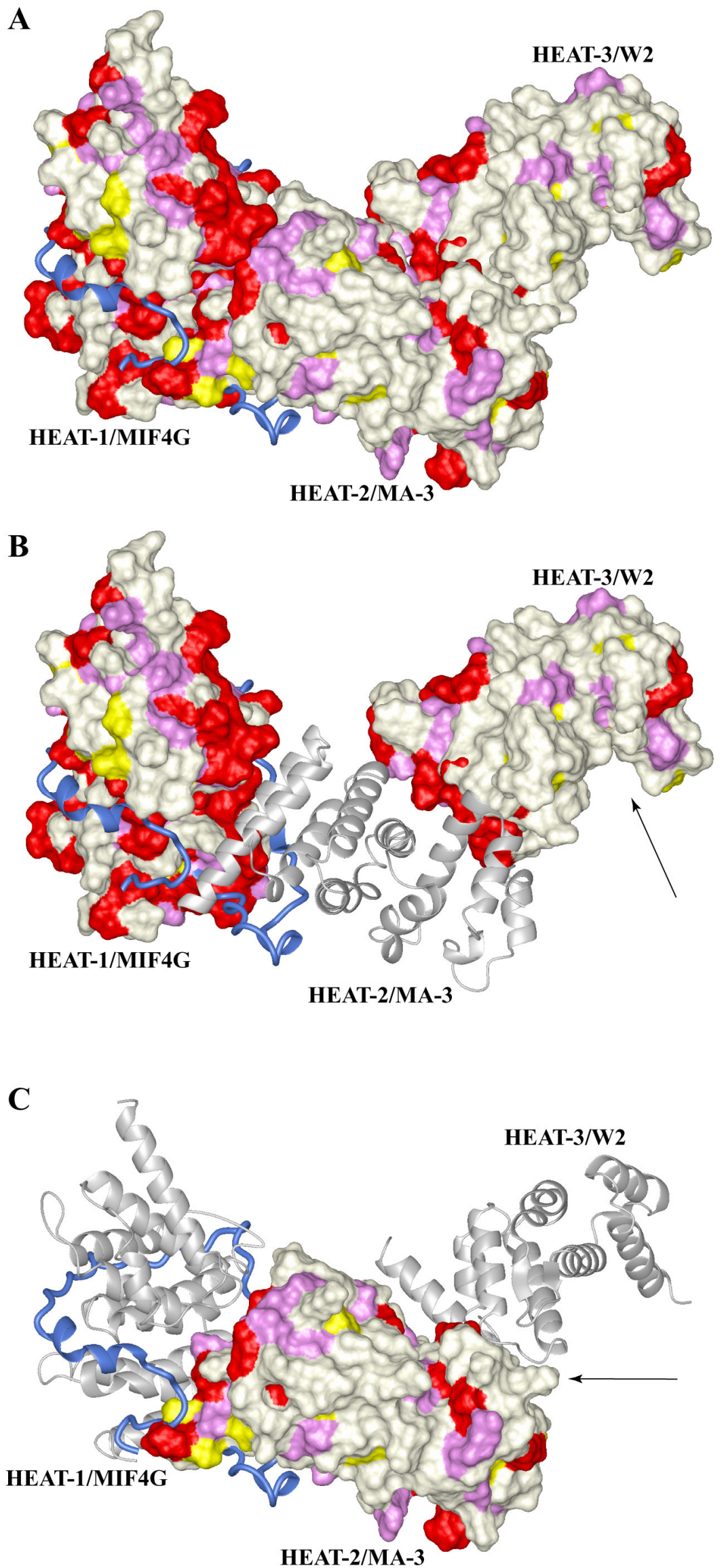